\title{
BMJ Open Association between night-shift work, sleep quality and health-related quality of life: a cross-sectional study among manufacturing workers in a middle- income setting
}

Yin Cheng Lim (1) , ${ }^{1,2}$ Victor C. W. Hoe, ${ }^{1,3}$ Azlan Darus, ${ }^{4}$ Nirmala Bhoo-Pathy ${ }^{1,5}$

To cite: Lim YC, Hoe VCW, Darus A, et al. Association between night-shift work, sleep quality and health-related quality of life: a cross-sectional study among manufacturing workers in a middleincome setting. BMJ Open 2020;10:e034455. doi:10.1136/ bmjopen-2019-034455

- Prepublication history for this paper is available online To view these files, please visit the journal online (http://dx.doi org/10.1136/bmjopen-2019034455).

Received 20 September 2019 Revised 05 May 2020

Accepted 12 May 2020
Check for updates

(C) Author(s) (or their employer(s)) 2020. Re-use permitted under CC BY-NC. No commercial re-use. See rights and permissions. Published by BMJ.

For numbered affiliations see end of article.

Correspondence to Dr Yin Cheng Lim; yclim529@gmail.com

\section{ABSTRACT}

Objectives Night-shift work may adversely affect health. This study aimed to determine the impact of night-shift work on health-related quality of life (HRQoL), and to assess whether sleep quality was a mediating factor.

Design A cross-sectional study.

Setting 11 manufacturing factories in Malaysia. Participants 177 night-shift workers aged 40-65 years old were compared with 317 non-night-shift workers.

Primary and secondary outcomes Participants completed a self-administered questionnaire on sociodemographics and lifestyle factors, 12-item Short Form Health Survey V.2 (SF-12v2) and the Pittsburgh Sleep Quality Index (PSQI). The Baron and Kenny's method, Sobel test and multiple mediation model with bootstrapping were applied to determine whether PSQI score or its components mediated the association between night-shift work and HRQoL.

Results Night-shift work was associated with sleep impairment and HRQOL. Night-shift workers had significantly lower mean scores in all the eight SF-12 domains $(p<0.001)$. Compared with non-night-shift workers, night-shift workers were significantly more likely to report poorer sleep quality, longer sleep latency, shorter sleep duration, sleep disturbances and daytime dysfunction $(p<0.001)$. Mediation analyses showed that PSQI global score mediated the association between night-shift work and HRQoL. 'Subjective sleep quality' (indirect effect $=-0.24, \mathrm{SE}=0.14$ and bias corrected $(\mathrm{BC})$ $95 \% \mathrm{Cl}-0.58$ to -0.01 ) and 'sleep disturbances' (indirect effect $=-0.79, \mathrm{SE}=0.22$ and $\mathrm{BC} 95 \% \mathrm{Cl}-1.30$ to -0.42 ) were mediators for the association between night-shift work and physical well-being, whereas 'sleep latency' (indirect effect $=-0.51, \mathrm{SE}=0.21$ and $\mathrm{BC} 95 \% \mathrm{Cl}-1.02$ to -0.16 ) and 'daytime dysfunction' (indirect effect $=-1.11$, $\mathrm{SE}=0.32$ and $\mathrm{BC} 95 \% \mathrm{Cl}-1.86$ to -0.58 ) were mediators with respect to mental well-being.

Conclusion Sleep quality partially explains the association between night-shift work and poorer HRQoL. Organisations should treat the sleep quality of night-shift workers as a top priority area for action to improve their employees' overall wellbeing.
Strengths and limitations of this study

- The strengths of the study lie in the methodologies used to assess mediation, including the classical method of Baron and Kenny, Sobel test and multiple mediation analysis with bootstrapping.

- Post-hoc mediation analyses were performed to determine whether other lifestyle factors may have explained the association between night-shift work and health-related quality of life.

- The nature of study limits the assessment of causal relationship and bidirectional effects.

\section{BACKGROUND}

Shift work is defined by the International Labour Organization as a 'method of organisation of working time in which workers succeed one another at the workplace so that the establishment can operate longer than the normal working hours of an individual'. ${ }^{1}$ As shift work is essential especially in manufacturing sectors to optimise productivity and maintain business competitiveness, it is widely adopted around the world. ${ }^{2}$

Shift work has been found to be associated with a myriad of adverse health impacts, including cardiovascular diseases, metabolic syndrome, cancers and reproductive disorders. $^{3-6}$ Furthermore, a number of studies have shown that night-shift work is associated with poor general well-being, as well as depression and anxiety. ${ }^{7-11}$ A study among more than 2000 women in Korea showed that working in rotating shift or night shift was associated with significantly poor healthrelated quality of life (HRQoL). ${ }^{12}$ HRQoL is defined as the way health is empirically estimated to affect QoL. ${ }^{13}$

Sleep disturbance is a common problem faced by night-shift workers. The sleep-wake cycle, which is regulated by the endogenous 
circadian rhythm, is disrupted by night-shift work. A number of studies have demonstrated that poor sleep quality and short sleep duration is associated with mood disturbances and lower subjective well-being. ${ }^{14} 15$ However, it remains unclear whether poor sleep quality explains the association between night-shift work and HRQoL. Previous studies examining the association between shift work and HRQoL have treated sleep quality as a confounder and not as a mediator. ${ }^{16} 17$

Given the scarcity of evidence and a high demand for night-shift work worldwide, more evidence is needed to improve our understanding on the impact of night-shift work on health. The first part of our study, which focused on the association between night-shift work and metabolic syndrome, has been published elsewhere. ${ }^{4}$ In the present work, we investigated the association between night-shift work and HRQoL, and assessed whether sleep quality was a mediating factor. Knowledge on whether sleep quality mediates this association will provide an avenue for early intervention to improve the overall well-being of nightshift workers. ${ }^{18}$

\section{METHODS}

\section{Study design}

This cross-sectional study was conducted between October 2015 and July 2016 among participants of the Social Security Organization's (SOCSO) Health Screening Programme (HSP). ${ }^{19}$ SOCSO is legislated to provide social security insurance to all private sector employees in Malaysia. ${ }^{19}$ The HSP was introduced by SOCSO in 2013 to provide free health screening for contributors aged 40 years and above. ${ }^{19}$ The details on the study and selection of participants had been described in our previously published paper, ${ }^{4}$ where 11 factories involved with manufacturing in the Klang Valley, Malaysia, that were registered with SOCSO were selected through convenience sampling. Invitation letters were sent to the respective human resource departments. All workers who participated in the HSP were invited to complete the study questionnaires. ${ }^{4}$ Out of 667 participants from the HSP, 510 workers fulfilled the criteria of no changes in their work schedule within 2 years prior to study recruitment. However, 16 participants failed to complete the study questionnaires, resulting in a final number of 494 participants.

\section{Data collection}

Data were collected using a self-administered Malay language questionnaire. The questionnaire included data on age, sex, ethnicity, education level and total income, participants' smoking status (ever or never) and alcohol intake (ever or never). The validated Malay version of International Physical Activity Questionnaire-Short Form was used to assess the level of physical activity. ${ }^{20}$

In the present study, night-shift work was defined as at least 8 hours of work between 0921:00 and 05:00, with at least 4 night shifts in a month. ${ }^{4}$ These include permanent night schedule, day-evening-night and day-night work schedules. Non-night-shift work comprised permanent daytime and day-evening-shift schedules. Sleep quality was assessed using the self-administered Pittsburgh Sleep Quality Index (PSQI) questionnaire. ${ }^{21}$ The tool comprises seven components of sleep, that is, subjective sleep quality, sleep latency, sleep duration, habitual sleep efficiency, sleep disturbance, use of sleep medication and daytime dysfunction. It has been translated into the Malay language, and proven to be a valid and reliable questionnaire. ${ }^{22}$ Each component of the questionnaire is rated on a 4-point scale (0-3), which generates a total score ranging between 0 and 21. A global score greater than five is an indication of poor sleep quality. ${ }^{21}$

HRQoL was assessed using 12-item Short Form Health Survey V.2 (SF-12v2), which is a shorter version of the 36-item Short Form Health Survey (SF-36) ${ }^{23}$ It measures eight domains of health and well-being under two overall scales, that is, Physical Component Summary (PCS) and Mental Component Summary (MCS) scales. The PCS assesses physical functioning, including walking, bending, stretching and climbing stairs, without limitation and problems of work or other daily activity resulting from the physical health. It consists of physical functioning, role limitations due to physical health, body pain and general health perceptions. The MCS, on the other hand, assesses general well-being, psychological distress, degree of happiness and limitations that emotional problems place on the extent of activities one is able to perform. ${ }^{23}$ It is made up of vitality, social functioning, role limitations due to emotional problems and mental health domains. The Malay version of SF-12v2 has been shown to have good internal consistency. ${ }^{24}$ The scoring of SF-12v2 was calculated using the Quality Metric Health Outcomes Scoring Software V.5.0. Each of the eight domains was scored out of 100 , with higher scores indicating better health status.

\section{Statistical analysis}

The demographic and lifestyle characteristics of participants were compared according to their shift work status. All categorical variables were described by proportions and compared using $\chi^{2}$ test. The non-parametric MannWhitney $\mathrm{U}$ test was used for asymmetrical continuous variables.

The Baron and Kenny's method and Sobel test ${ }^{4}$ were applied to assess whether the association between nightshift work and HRQoL was mediated by the PSQI global score. According to Baron and Kenny's criteria, ${ }^{25}$ four statistical conditions need to be met to establish complete mediation or partial mediation. (1) Path c: night-shift work (independent variable) should significantly influence HRQoL (dependent variable). (2) Path a: nightshift work (independent variable) should significantly influence PSQI global score (mediator). (3) Path b: PSQI global score (mediator) should also significantly influence HRQoL (dependent variable) when adjusted for night-shift work status (independent variable). (4) Path $c^{\prime}$ : mediation occurs if when Paths a and $\mathrm{b}$ are controlled, 
the significant association between night-shift work (independent variable) and HRQoL (dependent variable) is attenuated or become non-significant. A complete mediation is established if the association between nightshift work and HRQoL is reduced to zero (Path $c^{\prime}$ ). The conceptual framework is shown in online supplementary material e-Figure 1 and summarised by the regression equations in online supplementary material e-Figure 2.

To explore sleep quality dimensions, multiple mediation analysis using the PROCESS macro on SPSS V.21 developed by Hayes was employed to test a multiple mediation model with the seven components of the PSQI. ${ }^{26}$ This test allows multiple mediators to be examined and covariates to be controlled simultaneously. ${ }^{26}$ Bootstrapping was conducted to enable the detection of an indirect effect in the absence of total effect. Coefficient for Paths $\mathrm{a}, \mathrm{b}$ and $\mathrm{c}$ were estimated using ordinary least squares regression. The mediation analysis was adjusted for age, sex, ethnicity, education level, total household income, marital status, alcohol consumption, smoking status and physical activity. Bias corrected (BC) $95 \%$ CI for the indirect effects were generated from 5000 bootstrap samples ${ }^{26}$; statistically, significance was indicated when the BC $95 \%$ CI values do not cross zero. ${ }^{26}$

The paths between night-shift work (independent variable), components of the PSQI (mediators) and physical/ mental well-being (dependent variable) are summarised in online supplementary material e-Figure 3: Paths a $\mathrm{a}_{1}-\mathrm{a} 7$ : night-shift work to each of the potential mediator; Paths $b_{1}-b_{7}$ : each of the potential mediators to physical/mental well-being; Path c: the total effect of night-shift work to physical/mental well-being and Path $c^{\prime}$ : the direct effect of night-shift work on physical/mental well-being after adjusting for the effect of the potential mediators.

\section{Patient and public involvement}

Study participants were not involved in the development of this study. The results from the blood investigation, along with the details of sleep quality and HRQoL, were discussed with the individual study participants during their follow-up visits.

\section{RESULTS}

A total of 494 workers from 11 manufacturing factories participated in the study, of whom 177 (36\%) were nightshift workers. Night-shift workers consisted of day-nightshift workers $(94 ; 53 \%)$, day-evening-night-shift workers $(75 ; 42 \%)$ and permanent night-shift workers $(8 ; 5 \%)$. Among the 317 non-night-shift workers (64\%), 253 were permanent daytime workers $(80 \%)$, while 64 were dayevening-shift workers (20\%). As compared with nonnight-shift worker, night-shift workers were younger (46 years old vs 47 years old), more likely to be female $(68 \%$ vs $38 \%)$ and predominantly of Malay ethnicity $(81 \%$ vs $68 \%)$. They also reported significantly lower income $(<$ RM5000 per month) and were less likely to have attained tertiary education ( $10 \%$ vs $27 \%)$ compared with non-night-shift workers. Detailed characteristics of study participants can be found in a previous publication. ${ }^{4}$

In general, night-shift workers had significantly lower mean scores in all eight SF-12 domains, which meant that night-shift workers reported substantially poorer HRQoL than non-night-shift workers (table 1). The largest difference was observed in the social functioning domain (44.39 vs 50.20) and the smallest difference in the vitality domain (52.90 vs 55.92). In addition, the summary scores showed a significantly lower SF-12 PCS (45.35 vs 48.58) and lower SF-12 MCS scores (47.31 vs 52.03) among night-shift

Table 1 The SF-12 and the PSQI scores divided according to night-shift work status

\begin{tabular}{|c|c|c|c|}
\hline \multirow[b]{3}{*}{ Parameters } & Night-shift workers & Non-night-shift workers & \multirow[b]{3}{*}{ P value* } \\
\hline & $(n=177)$ & $(n=317)$ & \\
\hline & Mean \pm SD & Mean \pm SD & \\
\hline General health perception & $42.07 \pm 9.06$ & $46.55 \pm 8.76$ & $<0.001$ \\
\hline Physical functioning & $46.91 \pm 8.75$ & $50.01 \pm 8.35$ & $<0.001$ \\
\hline Body pain & $45.43 \pm 8.91$ & $48.77 \pm 8.02$ & $<0.001$ \\
\hline Mental health & $47.39 \pm 7.99$ & $51.34 \pm 8.26$ & $<0.001$ \\
\hline Vitality & $52.90 \pm 8.12$ & $55.92 \pm 9.24$ & $<0.001$ \\
\hline Social functioning & $44.39 \pm 8.66$ & $50.20 \pm 8.38$ & $<0.001$ \\
\hline PSQI global score & $6.3 \pm 2.6$ & $4.8 \pm 2.8$ & $<0.001$ \\
\hline
\end{tabular}

*Non-parametric Mann-Whitney U Test.

PSQI, Pittsburgh Sleep Quality Index; ; SF-12, 12-item Short Form Health Survey. 
workers compared with non-night-shift workers. The mean PSQI global score for night-shift workers was higher $(6.3 \pm 2.6)$ as compared with non-night-shift workers $(4.8 \pm 2.8, \mathrm{p}<0.001$ and $95 \%$ CI 1.01 to 1.99$)$, indicating poorer quality of sleep (table 1 ). Compared with nonnight shift workers, night-shift workers were significantly more likely to report longer sleep latency, poorer sleep quality, more sleep disturbances, shorter sleep duration and daytime dysfunction. The details of sleep quality can be found in our previously published paper. ${ }^{4}$

Mediation analysis using the Baron and Kenny's method (online supplementary material e-Figures 4 and 5) revealed that: (1) Path c: night-shift work was significantly associated with SF-12 PCS (unstandardised $\beta$ coefficient, $\beta=-3.24, \mathrm{SE}=0.64$ and $\mathrm{p}<0.001)$ and $\mathrm{SF}-12$ MCS $(\beta=-4.72, S E=0.77$ and $p<0.001)$, (2) Path a: nightshift work was significantly associated with PSQI global score $(\beta=1.50, \mathrm{SE}=0.25$ and $\mathrm{p}<0.001)$, (3) Path b: PSQI global score was significantly associated with SF-12 PCS $(\beta=-0.57, \mathrm{SE}=0.11$ and $p=0.001)$ and SF-12 MCS $(\beta=-0.71$, $\mathrm{SE}=0.13$ and $\mathrm{p}<0.001)$ and (4) Path $\mathrm{c}^{\prime}$ : after controlling for PSQI global score, night-shift work was still a significant predictor for SF-12 PCS $(\beta=-2.30, \mathrm{SE}=0.67$ and $\mathrm{p}<0.001)$ and SF-12 MCS $(\beta=-3.42, \mathrm{SE}=0.80$ and $\mathrm{p}<0.001)$. Thus, the associations between night-shift work and SF-12 PCS, and SF-12 MCS seem to be partially mediated by PSQI global score.
The mediating effects of the seven individual components of the PSQI on the association between night-shift work and physical well-being were additionally tested (table 2). Beyond the effects of covariates, the only significant mediators were 'subjective sleep quality' (indirect effect $=-0.24, \mathrm{SE}=0.14$ and BC $95 \%$ CI -0.58 to -0.01 ) and 'sleep disturbances' (indirect effect $=-0.79, \mathrm{SE}=0.22$ and BC $95 \%$ CI -1.30 to -0.42 ). Indirect effects through 'subjective sleep quality' and 'sleep disturbances' were significant as the point estimate for these two components did not cross zero. The total indirect effect was statistically significant (indirect effect $=-1.43, \mathrm{SE}=0.33$, BC $95 \%$ CI -2.15 to -0.84$)$. In term of effect ratio, the contribution of subjective sleep quality and sleep disturbances components as mediators in the association between night-shift work and SF-12 PCS was $8 \%$ and $21 \%$, respectively.

On the other hand, 'sleep latency' (indirect effect $=-0.51, \mathrm{SE}=0.21$ and $\mathrm{BC} 95 \% \mathrm{CI}-1.02$ to -0.16$)$ and 'daytime dysfunction' (indirect effect $=-1.11, \mathrm{SE}=0.32$ and BC $95 \%$ CI -1.86 to -0.58 ) were found to mediate the association between night-shift work and mental well-being (table 3). The total indirect effect was statistically significant (indirect effect $=-2.14, \mathrm{SE}=0.39$ and $\mathrm{BC}$ $95 \%$ CI -3.00 to -1.43$)$. The contribution of sleep latency and daytime dysfunction as mediators in the association between night-shift work and mental well-being was $10 \%$

\begin{tabular}{|c|c|c|c|c|c|c|c|c|c|c|c|}
\hline \multirow{2}{*}{$\begin{array}{l}\text { Potential } \\
\text { mediators }\end{array}$} & \multicolumn{2}{|c|}{ Path a } & \multicolumn{2}{|c|}{ Path b } & \multicolumn{2}{|c|}{ Path c } & \multicolumn{2}{|c|}{ Path c' } & \multicolumn{3}{|c|}{ Path ab } \\
\hline & $\beta$ (SE) & $P$ value & $\beta$ (SE) & $P$ value & $\beta$ (SE) & $P$ value & $\beta$ (SE) & $P$ value & Path & $\beta$ (SE) & BC $95 \% \mathrm{Cl}^{*}$ \\
\hline Sleep latency & $\begin{array}{l}0.46 \\
(0.09)\end{array}$ & $<0.001$ & $\begin{array}{l}-0.53 \\
(0.34)\end{array}$ & 0.113 & & & & & $a_{2} b_{2}$ & $\begin{array}{l}-0.24 \\
(0.15)\end{array}$ & -0.61 to 0.01 \\
\hline $\begin{array}{l}\text { Habitual sleep } \\
\text { efficiency }\end{array}$ & $\begin{array}{l}-0.11 \\
(0.07)\end{array}$ & 0.146 & $\begin{array}{l}0.03 \\
(0.44)\end{array}$ & 0.954 & & & & & $a_{4} b_{4}$ & $\begin{array}{l}-0.01 \\
(0.05)\end{array}$ & -0.12 to 0.10 \\
\hline $\begin{array}{l}\text { Sleep } \\
\text { disturbances }\end{array}$ & $\begin{array}{l}0.32 \\
(0.05)\end{array}$ & $<0.001$ & $\begin{array}{l}-2.50 \\
(0.59)\end{array}$ & $<0.001$ & & & & & $a_{5} b_{5}$ & $\begin{array}{l}-0.79 \\
(0.22)\end{array}$ & $\begin{array}{l}-1.30 \text { to } \\
-0.42\end{array}$ \\
\hline $\begin{array}{l}\text { Use of sleep } \\
\text { medications }\end{array}$ & $\begin{array}{l}0.01 \\
(0.03)\end{array}$ & 0.854 & $\begin{array}{l}-1.54 \\
(0.99)\end{array}$ & 0.120 & & & & & $a_{6} b_{6}$ & $\begin{array}{l}-0.01 \\
(0.06)\end{array}$ & -0.18 to 0.08 \\
\hline & \multicolumn{6}{|c|}{ Total indirect effects } & & & $A B$ & $\begin{array}{l}-1.43 \\
(0.33)\end{array}$ & $\begin{array}{l}-2.15 \text { to } \\
-0.84\end{array}$ \\
\hline
\end{tabular}

Mediation analysis performed by PROCESS macro.

Adjusted for age (continuous), sex, ethnicity, education level, total household income, marital status, alcohol consumption, smoking status, physical activity, known case of diabetes, hypertension and dyslipidaemia.

Path a: night-shift work to each of the seven potential mediators.

Path b: each of the seven potential mediators to PCS.

Path c (total effect): night-shift work to PCS.

Path c' (direct effect): night-shift work to PCS, controlling for mediators.

Path $a_{1} b_{1}-a_{7} b_{7}$ (specific indirect effects): $a_{1} b_{1}$, night-shift work to PCS through subjective sleep quality. This pattern continues for $a_{2} b_{2}-a_{7} b_{7}$. Path $A B$ (total indirect effect): night-shift work to PCS through each of the seven dimensions of PSQI.

Effect ratio: $\beta$ in specific indirect effect/B in total effect.

${ }^{*} \mathrm{BC} 95 \% \mathrm{Cls}$ after running 5000 bootstrap samples.

$\beta$, unstandardised beta coefficient; BC 95\% Cl, bias corrected 95\% CI; PCS, Physical Component Summary; PSQI, Pittsburgh Sleep Quality Index.; 
Table 3 Mediation model between night-shift work and MCS as mediated by components of PSQI

\begin{tabular}{|c|c|c|c|c|c|c|c|c|c|c|c|}
\hline \multirow[b]{2}{*}{$\begin{array}{l}\text { Potential } \\
\text { mediators }\end{array}$} & \multicolumn{2}{|c|}{ Path a } & \multicolumn{2}{|c|}{ Path b } & \multicolumn{2}{|c|}{ Path c } & \multicolumn{2}{|c|}{ Path c' } & \multicolumn{3}{|c|}{ Path ab } \\
\hline & $\begin{array}{l}\beta \\
\text { (SE) }\end{array}$ & $P$ value & $\begin{array}{l}\beta \\
\text { (SE) }\end{array}$ & $P$ value & $\begin{array}{l}\beta \\
\text { (SE) }\end{array}$ & $P$ value & $\begin{array}{l}\beta \\
\text { (SE) }\end{array}$ & P value & Path & $\begin{array}{l}\beta \\
\text { (SE) }\end{array}$ & BC $95 \% \mathrm{Cl}^{*}$ \\
\hline Sleep latency & $\begin{array}{l}0.46 \\
(0.09)\end{array}$ & $<0.001$ & $\begin{array}{l}-1.11 \\
(0.40)\end{array}$ & 0.006 & & & & & $a_{2} b_{2}$ & $\begin{array}{l}-0.51 \\
(0.21)\end{array}$ & $\begin{array}{l}-1.02 \text { to } \\
-0.16\end{array}$ \\
\hline $\begin{array}{l}\text { Habitual sleep } \\
\text { efficiency }\end{array}$ & $\begin{array}{l}-0.11 \\
(0.07)\end{array}$ & 0.146 & $\begin{array}{l}0.78 \\
(0.52)\end{array}$ & 0.137 & & & & & $a_{4} b_{4}$ & $\begin{array}{l}-0.08 \\
(0.08)\end{array}$ & $\begin{array}{l}-0.34 \text { to } \\
0.02\end{array}$ \\
\hline $\begin{array}{l}\text { Sleep } \\
\text { disturbances }\end{array}$ & $\begin{array}{l}0.32 \\
(0.05)\end{array}$ & $<0.001$ & $\begin{array}{l}-0.51 \\
(0.70)\end{array}$ & 0.466 & & & & & $a_{s} b_{s}$ & $\begin{array}{l}-0.16 \\
(0.23)\end{array}$ & $\begin{array}{l}-0.62 \text { to } \\
0.28\end{array}$ \\
\hline $\begin{array}{l}\text { Use of sleep } \\
\text { medications }\end{array}$ & $\begin{array}{l}0.01 \\
(0.03)\end{array}$ & 0.854 & $\begin{array}{l}1.27 \\
(1.18)\end{array}$ & 0.280 & & & & & $a_{6} b_{6}$ & $\begin{array}{l}0.01 \\
(0.05)\end{array}$ & $\begin{array}{l}-0.07 \text { to } \\
0.16\end{array}$ \\
\hline
\end{tabular}

Mediation analysis performed by PROCESS macro.

All analysis is adjusted for age (continuous), sex, ethnicity, education level, total income, marital status, alcohol intake, smoking status, physical activity, known case of diabetes, hypertension and dyslipidaemia.

Path a: night-shift work to each of the seven potential mediators.

Path b: each of the seven potential mediators to SF-12 PCS.

Path c (total effect): night-shift work to SF-12 MCS.

Path $c^{\prime}$ (direct effect): night-shift work to SF-12 MCS, controlling for mediators.

Path $a_{1} b_{1}-a_{7} b_{7}$ (specific indirect effect): $a_{1} b_{1}$, night-shift work to SF-12 MCS through subjective sleep quality. This pattern continues for $a_{2} b_{2}-a_{7} b_{7}$.

Path AB (total indirect effect): night-shift work to SF-12 MCS through individual components of the PSQI.

Effect ratio: $\beta$ in specific indirect effect/B in total effect.

${ }^{*} \mathrm{BC} 95 \%$ Cls after running 5000 bootstrap samples.

$\beta$, unstandardised beta coefficient; BC 95\% Cl, bias corrected 95\% Cl; MCS, Mental Component Summary; PSQI, Pittsburgh Sleep Quality Index; ;

SF-12, 12-item Short Form Health Survey.

\begin{tabular}{|c|c|c|c|c|c|c|c|c|c|c|c|}
\hline \multirow[b]{2}{*}{$\begin{array}{l}\text { Potential } \\
\text { mediators }\end{array}$} & \multicolumn{2}{|c|}{ Path a } & \multicolumn{2}{|c|}{ Path b } & \multicolumn{2}{|c|}{ Path c } & \multicolumn{2}{|c|}{ Path c' } & \multicolumn{3}{|c|}{ Path ab } \\
\hline & $\begin{array}{l}\beta \\
\text { (SE) }\end{array}$ & $P$ value & $\begin{array}{l}\beta \\
\text { (SE) }\end{array}$ & $P$ value & $\begin{array}{l}\beta \\
\text { (SE) }\end{array}$ & $P$ value & $\begin{array}{l}\beta \\
\text { (SE) }\end{array}$ & $P$ value & Path & $\begin{array}{l}\beta \\
\text { (SE) }\end{array}$ & $\mathrm{BC} 95 \% \mathrm{Cl}^{\star}$ \\
\hline PCS & $\begin{array}{l}-2.75 \\
(0.69)\end{array}$ & $<0.001$ & $-0.10(0.02)$ & $<0.001$ & $\begin{array}{l}1.50 \\
(0.27)\end{array}$ & $<0.001$ & $\begin{array}{l}0.86 \\
(0.27)\end{array}$ & 0.001 & $a_{1} b_{1}$ & $\begin{array}{l}0.28 \\
(0.08)\end{array}$ & 0.12 to 0.47 \\
\hline MCS & $\begin{array}{l}-3.89 \\
(0.79)\end{array}$ & $<0.001$ & $-0.09(0.01)$ & $<0.001$ & & & & & $a_{2} b_{2}$ & $\begin{array}{l}0.34 \\
(0.09)\end{array}$ & 0.17 to 0.56 \\
\hline
\end{tabular}

Mediation analysis performed by PROCESS macro.

All analysis is adjusted for age (continuous), sex, ethnicity, education level, total income, marital status, alcohol intake, smoking status, physical activity, known case of diabetes, hypertension and dyslipidaemia.

Path a: night-shift work to each of the two potential mediators.

Path b: Each of the two potential mediators to PSQI global score.

Path c (total effect): night-shift work to sleep impairment.

Path c' (direct effect): night-shift work to sleep impairment, controlling for mediators.

Path $a_{1} b_{1}-a_{2} b_{2}$ (specific indirect effect): $a_{1} b_{1}$, night-shift work to sleep impairment through PCS. This pattern continues for $a_{2} b_{2}$.

Path AB (total indirect effect): night-shift work to PSQI global score through individual component summary of SF-12.

Effect ratio: $\beta$ in specific indirect effect/B in total effect.

${ }^{*} \mathrm{BC} 95 \%$ Cls after running 5000 bootstrap samples.

$\beta$, unstandardised beta coefficient; BC 95\% Cl, bias corrected 95\% Cl; MCS, Mental Component Summary; PCS, Physical Component Summary;

PSQI, Pittsburgh Sleep Quality Index.; 
and $26 \%$, respectively. In contrast, other components of PSQI did not appear to mediate the association.

Reverse modelling was conducted to determine whether the association between night-shift work and sleep impairment (PSQI global score $>5$ ) was mediated by physical and mental well-being (table 4). Indirect effects through physical well-being (indirect effect $=0.28, \mathrm{SE}=0.08$ and BC $95 \%$ CI 0.12 to 0.47 ) and mental well-being (indirect effect $=0.34, \mathrm{SE}=0.09$ and $\mathrm{BC} 95 \% \mathrm{CI} 0.17$ to 0.56 ) were significant as the point estimates for both SF-12 PCS and SF-12 MCS did not cross zero. Effect ratio revealed that the contribution of physical and mental well-being as mediators in the association between night-shift work and sleep impairment was $19 \%$ and $23 \%$, respectively.

Given that the association between nightshift work and HRQoL was not completely mediated by sleep quality, post-hoc analysis was performed to assess whether other lifestyle factors may have mediated the association. Analyses using Baron and Kenny's criteria (data not shown) and Sobel test showed that neither smoking status $(Z=0.05$ and $\mathrm{p}=0.963)$, alcohol intake $(\mathrm{Z}=0.94$ and $\mathrm{p}=0.346)$ nor physical activity $(\mathrm{Z}=0.86$ and $\mathrm{p}=0.389)$ mediated the association between night-shift work and physical wellbeing and neither smoking status $(\mathrm{Z}=0.42$ and $\mathrm{p}=0.675)$, alcohol intake $(\mathrm{Z}=0.42$ and $\mathrm{p}=0.675)$ nor physical activity $(\mathrm{Z}=0.84$ and $\mathrm{p}=0.375)$ mediated the association between night-shift work and mental well-being (data not shown).

\section{DISCUSSION}

Our current study findings suggest that night-shift work is associated with lower HRQoL compared with non-nightshift work, on both the physical and mental well-being domains. This association appears to be partially mediated by sleep quality.

Our finding that night-shift workers were associated with worst sleep quality compared with non-night-shift workers is consistent with findings from previous studies. ${ }^{727}$ Sleep deprivation had received increasing attention for its adverse impact on HRQoL. The current results are also in agreement with prior studies investigating the association between sleep and general well-being, which have indicated that poor sleep quality is detrimental to the physical and mental well-being. ${ }^{28}{ }^{29}$ This is corroborated further by findings of a clinical trial, in which use of hypnosis to treat participants with insomnia resulted in significant improvements in several domains of the SF-36. ${ }^{30}$ Besides being associated with poorer HRQoL, a meta-analysis of 34 cohort studies had reported that insomnia is significantly associated with depression (Relative Risk $(\mathrm{RR})=2.27$ and $95 \%$ CI 1.89 to 2.71$),{ }^{31}$ whereby depression is found to have severe impact on HRQoL. ${ }^{32}$

There are several mechanistic pathways that have been postulated to explain the association between poor sleep quality and poor HRQoL. Firstly, night-shift work is associated with reduction in production of melatonin, given that its production takes place in darkness and is inhibited by exposure to bright light at night. ${ }^{33}$ There is evidence showing that treatment with melatonin may improve quality of life in cancer patients and epileptic children. $^{3435}$ Secondly, poor sleep quality leads to the activation of the sympathetic nervous system via the hypothalamic-pituitary-adrenal axis. ${ }^{36}$ This in turn will lead to alteration of metabolic and endocrine functions, which has been found to be associated with poor HRQoL. ${ }^{37}$ Finally, the increased levels of $\mathrm{C}$ reactive protein and interleukin-6 due to poor sleep quality have been found to be associated with poor HRQoL. ${ }^{38}$

Our study showed that sleep quality appears to be a significant mediator in the association between night-shift work and HRQoL. Further analysis showed that the association between night-shift work and physical well-being was mediated through 'subjective sleep quality' and 'sleep disturbances', whereas the association between nightshift work and mental well-being was mediated through 'sleep latency' and 'daytime dysfunction'. These findings have not been reported previously and warrant further investigation.

Besides sleep, other possible mediators such as stress and sedentary lifestyle may link night-shift work and HRQoL. Stress due to night-shift work might lead to lower HRQoL. ${ }^{39}$ Besides the above, shift workers are also likely to lead unhealthy lifestyles, such as low recreational physical activity and smoking, which have been found to be associated with lower HRQoL. ${ }^{40}$ In view of the above, in addition to adjusting for smoking status, alcohol intake and physical activity in the multivariable analysis, post-hoc analyses were performed to determine whether any of the above-mentioned lifestyle factors acted as mediators in the association between night-shift work and HRQoL. However, our findings suggest that these lifestyle factors do not mediate the association between night-shift work and HRQoL.

We acknowledge some limitations of the present study. The nature of this study limits our ability to explain causal relationships and bi-directional effects among shift work, sleep quality and HRQoL. Reverse causation whereby lower HRQoL leads to poorer sleep quality is possible. A lower HRQoL could in itself manifest as psychological distress, ${ }^{32}$ which is also known to affect sleep quality. ${ }^{41}$ There is a possibility of misclassification, since shift work, sleep quality and HRQoL were self-reported. Even though sleep was not measured objectively using actigraphy or polysomnography, it should be noted that the PSQI is a validated tool for measuring sleep quality. The information on the chronotype, stress levels and drug history (anxiolytics, hypnotics or psychotropics) of the participants were not collected; thus, the confounding effects of these factors were not evaluated. Finally, the sample size is relatively small.

The novelty of our present work lies in the robust mediation analysis that we had employed to ascertain the role of sleep quality as a potential mediating factor in the association between night-shift work and HRQoL. Apart from the above, we also undertook post-hoc mediation analyses to determine whether other lifestyle factors may 
have explained the association between shift work and HRQoL.

\section{CONCLUSION}

The findings from this study underscore the importance of monitoring sleep quality among night-shift workers. There is an urgent need for development and implementation of multidisciplinary interventions focusing on the improvement of sleep quality in affected nightshift workers. Nonetheless, any such intervention strategies, including medications such as modafinil and melatonin supplement, cognitive-behavioural therapy and education programmes, must be tested for effectiveness through randomised trials. ${ }^{18}$ Future studies aiming to unravel other potential mediators linking night-shift work and HRQoL are also warranted to improve the overall well-being of employees, as better HRQoL has been found to be significantly associated with higher productivity.

\section{Author affiliations}

${ }^{1}$ Department of Social and Preventive Medicine, Faculty of Medicine, University of Malaya, Kuala Lumpur, Malaysia

${ }^{2}$ Environmental Health Research Centre, Institute Medical Research (IMR), National Institute of Health, Kuala Lumpur, Malaysia

${ }^{3}$ Centre for Occupational and Environmental Health, Faculty of Medicine, University of Malaya, Kuala Lumpur, Malaysia

${ }^{4}$ Social Security Organization, Kuala Lumpur, Malaysia

${ }^{5}$ Centre for Epidemiology and Evidence-Based Practice, Faculty of Medicine, University of Malaya, Kuala Lumpur, Malaysia

Acknowledgements The authors would like to thank the Director General of Health, Malaysia, for his permission to publish this paper. The authors are most grateful to all the participants of this study. We also would like to acknowledge Social Security Organization's for their assistance and permission to use data from Health Screening Programme.

Contributors The study conception was by YCL and NB-P. YCL, VH and NB-P designed the study, conducted the statistical analysis and interpreted the results. YCL and AD collected the data. YCL, VH, AD and NB-P drafted the manuscript. All authors have read and approved the final version of the submitted manuscript.

Funding This study was funded by the University Malaya Post-Graduate Research Fund (PG139-2015A). Funding for publication was from the National Institutes of Health, Ministry of Health, Malaysia.

Competing interests None declared.

Patient consent for publication Not required.

Ethics approval Ethical approval was obtained from Medical Ethics Committee of University of Malaya Medical Centre (MECID.NO: 20 154-1234).

Provenance and peer review Not commissioned; externally peer reviewed.

Data availability statement Data are available in a public, open access repository. Data are available upon reasonable request. Extra data can be accessed via the Dryad data repository at http://datadryad.org/ with the doi: 10.5061/ dryad.905qftthw.

Open access This is an open access article distributed in accordance with the Creative Commons Attribution Non Commercial (CC BY-NC 4.0) license, which permits others to distribute, remix, adapt, build upon this work non-commercially, and license their derivative works on different terms, provided the original work is properly cited, appropriate credit is given, any changes made indicated, and the use is non-commercial. See: http://creativecommons.org/licenses/by-nc/4.0/.

\section{ORCID iD}

Yin Cheng Lim http://orcid.org/0000-0002-8519-7046
REFERENCES

1 International Labour Office. Night work convention. Geneva, 1990.

2 Messenger JC, Lee S, McCann D. Working time around the world: trends in working hours, laws, and policies in a global comparative perspective. New York: Routledge, 2007.

3 Wang F, Yeung KL, Chan WC, et al. A meta-analysis on doseresponse relationship between night shift work and the risk of breast cancer. Ann Oncol 2013;24:2724-32.

4 Lim YC, Hoe VCW, Darus A, et al. Association between night-shift work, sleep quality and metabolic syndrome. Occup Environ Med 2018;75:716-23.

5 Wang X-S, Armstrong MEG, Cairns BJ, et al. Shift work and chronic disease: the epidemiological evidence. Occup Med 2011;61:78-89.

6 Bonzini M, Palmer KT, Coggon D, et al. Shift work and pregnancy outcomes: a systematic review with meta-analysis of currently available epidemiological studies. BJOG 2011;118:1429-37.

7 Lin P-C, Chen C-H, Pan S-M, et al. Atypical work schedules are associated with poor sleep quality and mental health in Taiwan female nurses. Int Arch Occup Environ Health 2012;85:877-84.

8 Selvi Y, Özdemir PG, Özdemir O, et al. Influence of night shift work on psychologic state and quality of life in health workers. Dusunen Adam 2010;23:238-43.

9 Ljoså CH, Tyssen R, Lau B. Mental distress among shift workers in Norwegian offshore petroleum industry--relative influence of individual and psychosocial work factors. Scand J Work Environ Health 2011;37:551-5.

10 Parkes KR, Shiftwork PKR. Shiftwork, job type, and the work environment as joint predictors of health-related outcomes. J Occup Health Psychol 1999;4:256.

11 Nena E, Katsaouni M, Steiropoulos P, et al. Effect of shift work on sleep, health, and quality of life of health-care workers. Indian $J$ Occup Environ Med 2018;22:29-34.

$12 \mathrm{Kim}$ W, Kim TH, Lee T-H, et al. The impact of shift and night work on health related quality of life of working women: findings from the Korea health panel. Health Qual Life Outcomes 2016;14:162.

13 Karimi M, Brazier J, Health BJ. Health, health-related quality of life, and quality of life: what is the difference? Pharmacoeconomics 2016;34:645-9.

14 Lemola S, Räikkönen K, Gomez V, et al. Optimism and self-esteem are related to sleep. results from a large community-based sample. Int J Behav Med 2013;20:567-71.

15 Magee CA, Caputi P, Iverson DC. Relationships between self-rated health, quality of life and sleep duration in middle aged and elderly Australians. Sleep Med 2011;12:346-50.

16 Boughattas W, Maalel OE, Chikh RB, et al. Hospital night shift and its effects on the quality of sleep, the quality of life, and vigilance troubles among nurses. Int J Clin Med 2014;05:572-83.

17 Cho H-S, Kim Y-W, Park H-W, et al. The relationship between depressive symptoms among female workers and job stress and sleep quality. Ann Occup Environ Med 2013;25:12.

18 McKenna H, Wilkes M. Optimising sleep for night shifts. BMJ 2018;360:j5637.

19 Social Security Organization. Secondary SOCSO health screening program, 2015. Available: http://sehat.perkeso.gov.my/component/ content/article/14-articles/141-faq

20 Chu AHY, Moy FM. Reliability and validity of the Malay international physical activity questionnaire (IPAQ-M) among a Malay population in Malaysia. Asia Pac J Public Health 2015;27:NP2381-9.

21 Buysse DJ, Reynolds CF, Monk TH, et al. The Pittsburgh sleep quality index: a new instrument for psychiatric practice and research. Psychiatry Res 1989;28:193-213.

22 Yunus RM, Wazid SW, Hairi NN, et al. Association between elder abuse and poor sleep: a cross-sectional study among rural older Malaysians. PLoS One 2017;12:e0180222.

23 Ware J, Kosinski M, Keller S. SF-12: how to score the SF-12 physical and mental health summary scales. Boston, United States: New England Medical Center, 1995.

24 Noor NM, Aziz AA. Validity and reliability of the Malay version of 12Item short form health survey among postpartum mothers. Malaysian J Public Health Med 2014;14:56-66.

25 Baron RM, Kenny DA. The moderator-mediator variable distinction in social psychological research: conceptual, strategic, and statistical considerations. J Pers Soc Psychol 1986;51:1173-82.

26 Hayes AF. Introduction to mediation, moderation, and conditional process analysis: a regression-based approach. New York: Guilford Press, 2018.

27 Monk TH, Buysse DJ, Billy BD, et al. Shiftworkers report worse sleep than day workers, even in retirement. $J$ Sleep Res 2013;22:201-8.

28 Hamilton NA, Nelson CA, Stevens N, et al. Sleep and psychological well-being. Soc Indic Res 2007;82:147-63. 
29 Steptoe A, O'Donnell K, Marmot M, et al. Positive affect, psychological well-being, and good sleep. J Psychosom Res 2008;64:409-15.

30 Walsh JK, Krystal AD, Amato DA, et al. Nightly treatment of primary insomnia with eszopiclone for six months: effect on sleep, quality of life, and work limitations. Sleep 2007;30:959-68.

31 Li L, Wu C, Gan Y, et al. Insomnia and the risk of depression: a meta-analysis of prospective cohort studies. BMC Psychiatry 2016;16:375.

32 Goldney RD, Phillips PJ, Fisher LJ, et al. Diabetes, depression, and quality of life: a population study. Diabetes Care 2004;27:1066-70.

33 Mirick DK, Bhatti P, Chen C, et al. Night shift work and levels of 6-sulfatoxymelatonin and cortisol in men. Cancer Epidemiol Biomarkers Prev 2013;22:1079-87.

34 Innominato PF, Lim AS, Palesh O, et al. The effect of melatonin on sleep and quality of life in patients with advanced breast cancer. Support Care Cancer 2016;24:1097-105.

35 Gupta M, Aneja S, Kohli K. Add-on melatonin improves quality of life in epileptic children on valproate monotherapy: a randomized, double-blind, placebo-controlled trial. Epilepsy Behav 2004;5:316-21.

36 Balbo M, Leproult R, Van Cauter E. Impact of sleep and its disturbances on hypothalamo-pituitary-adrenal axis activity. Int $J$ Endocrinol 2010;2010:1-16.

37 Fernandez-Mendoza J, Vgontzas AN. Insomnia and its impact on physical and mental health. Curr Psychiatry Rep 2013;15:418

38 de Almeida Roediger M, de Fátima Nunes Marucci M, Duim EL, et al. Inflammation and quality of life in later life: findings from the health, well-being and aging study (SABE). Health Qual Life Outcomes 2019;17:26.

39 Yang X, Ge C, Hu B, et al. Relationship between quality of life and occupational stress among teachers. Public Health 2009;123:750-5.

40 Senbanjo R, Wolff K, Marshall J. Excessive alcohol consumption is associated with reduced quality of life among methadone patients. Addiction 2007;102:257-63.

41 Demirci K, Akgönül M, Akpinar A. Relationship of smartphone use severity with sleep quality, depression, and anxiety in university students. J Behav Addict 2015;4:85-92. 